\title{
Two step method for rail potential rise analysis in a DC traction power supply system
}

\author{
S. Chung, H. Kim \& H. Jeong \\ Electric Power Supply Research Division, \\ Korea Railroad Research Institute, Korea
}

\begin{abstract}
An algorithm for analyzing the rail potentials in a DC traction power supply system is proposed. The distinctive feature of this algorithm is that it uses the node voltage method twice in the rail potential analysis. To calculate the rail potentials, the leakage resistance of the running rail must be included in the equivalent network which makes it difficult to apply the node voltage method. The mesh current method has the drawback that the initial mesh currents are difficult to estimate, which is necessary for an iterative network solution. In this algorithm, the rail potentials are obtained by applying the node voltage method twice. In the first stage, the injection currents to the negative rail are obtained from a load-flow study. In the next stage, a network consisting of the negative rail and the injection currents is constructed. The leakage resistance to ground is added to the network a, and the rail potentials of the network are analyzed. A computer load flow analysis software package was developed to verify the validity of the algorithm. The results from the software are compared with the EMTP-RV circuit analysis results, and the results are nearly identical.
\end{abstract}

Keywords: rail potential, simulation, DC traction power.

\section{Introduction}

In most DC powered electric railways, running rails are also used as the negative return path to the rectifier negative bus in the substation. In this system, the potentials of the running rails rise with increasing load current. The increased rail potential causes concern for human safety, due to the possibly hazardous excessive touch voltage and step voltages [1]. For this reason, the maximum allowable rail potential is limited by IEC standard 62128 [3]. The rail potential 
rise can also generate stray currents, which causes concern for equipment safety due to the possibility of electro-chemical corrosion of the metal [1].

In this paper, a computer algorithm to analyze the rail potential rise is presented. The distinctive feature of this algorithm is that it uses the node voltage method twice in the rail potential analysis. In the node voltage network analysis method, every node has to be directly connected to the reference node. However, if the leakage resistance of the running rail to ground is included, it becomes difficult to make an equivalent network in which every node is directly connected to the reference node. Under these conditions, the mesh current method may be used to solve the network. However, the mesh current network method has some drawbacks in this situation because it is difficult to set the initial mesh currents for iterative network analysis.

In the proposed algorithm, node voltage network analysis is conducted twice. First, the load flow is studied to obtain the injection currents to the substations and trains. The leakage resistance of the running rail is not modeled explicitly in this step, which makes every node in the equivalent circuit directly connected to the reference node. In the next step, a different node voltage equivalent circuit is constructed, with only the longitudinal resistance of the negative rail and the injection currents. The leakage resistance of the running rails is added to the equivalent circuit. A set of node equations is constructed to analyze the circuit and solve for the node voltages, corresponding to the potentials of the running rail at the corresponding locations. In conclusion, by conducting node voltage analysis twice, we can avoid using the mesh current method, which is difficult to use in traction power supply system analysis. The leakage current can be calculated from the rail potentials. Computer load flow analysis software using the algorithm was developed. A test run was conducted on a test system. The result is compared with the results of EMTP-RV circuit analysis, where the potentials of the running rail were calculated in one step. The comparison shows that the two results are nearly identical.

\section{Review of rail potential analysis}

A simple railway DC power feeding system is shown in Fig. 1, to illustrate the method for analyzing negative rail potentials [2]. The rail potentials at the rectifier station end and the train end are:

$$
\begin{gathered}
\mathrm{V}_{\mathrm{GL}}=\frac{\mathrm{R}_{\mathrm{L}}}{\mathrm{R}_{\mathrm{L}}+\mathrm{R}_{\mathrm{S}}} \cdot \mathrm{V}_{\mathrm{N}} \\
\mathrm{V}_{\mathrm{GS}}=-\frac{\mathrm{R}_{\mathrm{S}}}{\mathrm{R}_{\mathrm{L}}+\mathrm{R}_{\mathrm{S}}} \cdot \mathrm{V}_{\mathrm{N}} \\
\mathrm{V}_{\mathrm{N}}=\mathrm{I}_{\mathrm{N}} \cdot \mathrm{R}_{\mathrm{N}}
\end{gathered}
$$

$R_{S}$ and $R_{L}$ are the effective resistance to ground at the rectifier station end and the train end, respectively. They are lumped resistances obtained by converting the distributed rail-earth conductance of the negative rail to a lumped pie 
resistance circuit. $R_{N}$ is the longitudinal resistance of the running rail. $I_{N}$ is the load current in the running rail. $\mathrm{V}_{\mathrm{N}}$ is the longitudinal voltage drop in the running rail.

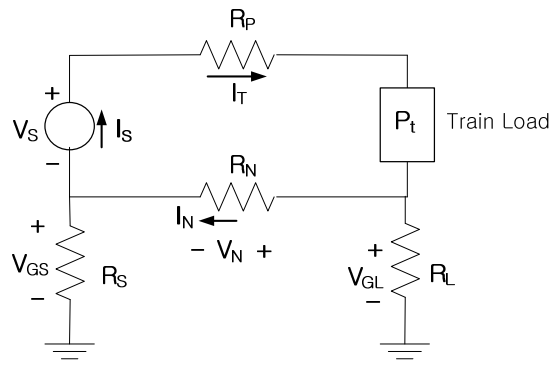

Figure 1: $\quad$ Basic model for rail potential analysis.

\section{Proposed computer algorithm for rail potential analysis}

Our purpose is to obtain the rail potentials, denoted by $\mathrm{V}_{\mathrm{GS}}$ and $\mathrm{V}_{\mathrm{GL}}$ in Fig. 1. To analyze the circuit in Fig. 1, the mesh current network shown in Fig. 2 has to be analyzed iteratively, which requires initial mesh currents. However, the initial value of $i_{2}$ in Fig. 2 is difficult to estimate. In the proposed algorithm, the node voltage analysis method is applied twice. In the first step, the leakage resistance of the running rail does not explicitly appear in the node voltage equivalent network, as shown in Fig. 3. In Fig. $3, R_{N}$ ' is the parallel resistance of $R_{N}$ and $\left(\mathrm{R}_{\mathrm{S}}+\mathrm{R}_{\mathrm{L}}\right) . \mathrm{P}_{\mathrm{t}}$ is the train load which is given. The circuit is analyzed iteratively to find the injection currents at the DC source nodes and the train nodes, which are $I_{s}$ and $I_{t}$ in Fig. 3. Fig. 2 and Fig. 3 are equivalent in terms of $I_{s}$ and $I_{t}$. In the next step, a different node voltage network is drawn, as shown in Fig. 4, with only the longitudinal resistance of the running rail and the injection currents. In Fig. 4, $I_{s}$ and $I_{t}$ are the injection currents obtained in step 1. The leakage resistance of the running rails is added to the equivalent circuit. The circuit in Fig. 4 is also equivalent to Fig. 2. if only the circuit elements in Fig. 4 are considered.

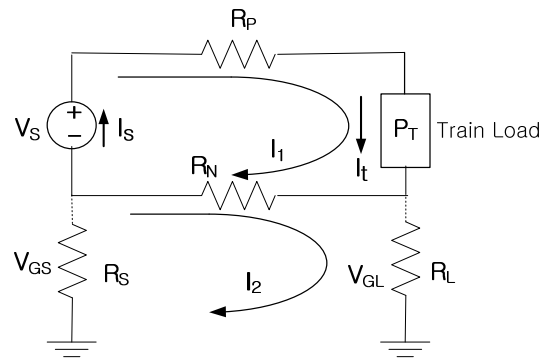

Figure 2: Mesh equivalent network of a simple DC traction power supply system. 


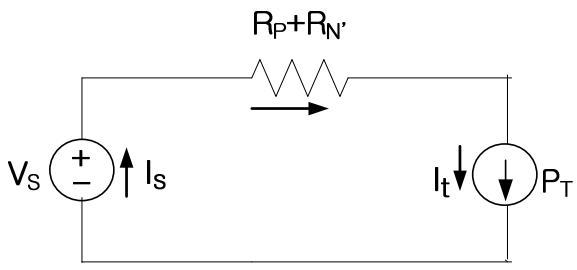

Figure 3: $\quad$ Node network in step 1 for the system in Fig. 2.

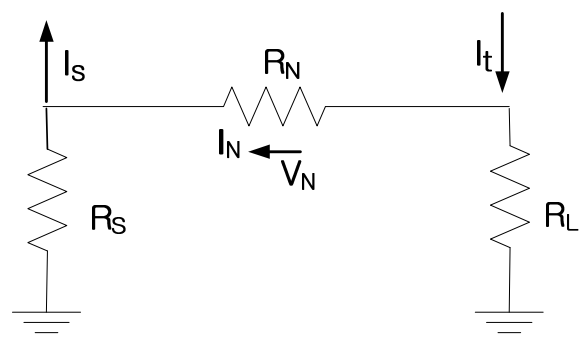

Figure 4: $\quad$ Node network in step 2 for the system in Fig. 2.

The logic flow diagram is shown in Fig. 5. In step 3 of the logic flow diagram, the node equation is constructed in matrix form, as shown in equation (4). Equation (4) is set for the circuit shown in Fig. 3.

$$
[\mathrm{G}][\mathrm{V}]=[\mathrm{I}]
$$

where $[\mathrm{G}]$ : the conductance matrix of the network

$[\mathrm{V}]:$ the node voltage vector

[I]: the node injection current vector

In eq. (4), the train load is given in terms of power instead of current or resistance. Given the required power of the train, the corresponding element in the [I] vector is obtained from eq. (5).

$$
I_{t}=-\frac{P_{t}}{V_{t}}
$$

where $\mathrm{P}_{\mathrm{t}}$ : the required power of the train

$\mathrm{I}_{\mathrm{t}}$ : the injection current at the train node

$\mathrm{V}_{\mathrm{t}}$ : the train node voltage (assumed value)

Because $I_{t}$ is a function of $V_{t}$, equation (4) is nonlinear, and must be solved iteratively. In step 4 of the logic flow diagram in Fig. 5, a new network is constructed, and a new set of node equations is built, as shown in eq.(6).

$$
[\mathrm{G}]_{\text {new }}[\mathrm{V}]_{\text {new }}=[\mathrm{I}]_{\text {new }}
$$

where $[\mathrm{G}]_{\text {new }}$ : the conductance matrix of the new network

$[\mathrm{V}]_{\text {new }}$ : the new network node voltage vector

$[\mathrm{I}]_{\text {new }}$ : the injection current vector, with elements corresponding to the source current or train load current 


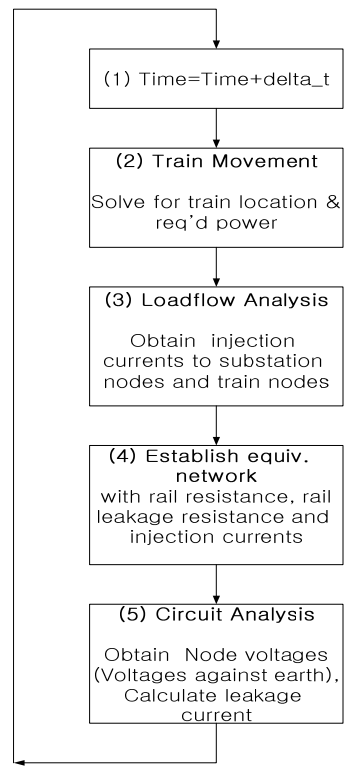

Figure 5: Logic flow diagram for the rail potential analysis.

Unlike equation (4), eq. (6) does not require an iterative solution because the elements of $[\mathrm{I}]_{\text {new }}$ are given as constants. All elements of $[\mathrm{V}]_{\text {new }}$ represent the running rail potential at every node location.

\section{Test run}

Computer load flow software for rail potential analysis was developed to implement the algorithm proposed above. It was applied to the test system, and the result was compared with the result of EMTP-RV analysis for the test system. Fig. 6 shows the test system, and the symbols in Fig. 6 are explained in Tables 1 and 2. In Fig. 6, m stands for 'milli-'. The line parameters and the train

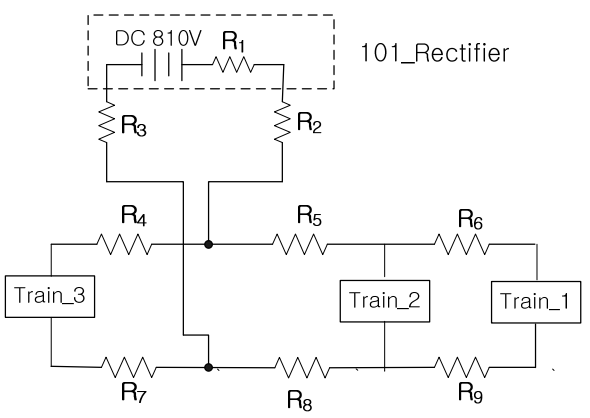

Figure 6: Test system. 
Table 1: $\quad$ Resistances in the test system.

\begin{tabular}{|c|c|c|}
\hline Symbol & Resistance $[\mathrm{m} \Omega]$ & Remark \\
\hline $\mathrm{R}_{1}$ & 22.5 & Internal resistance of DC source \\
\hline $\mathrm{R}_{2}$ & 0.35 & $\begin{array}{c}\text { Cable resistance between source } \\
\text { and positive feeding line }\end{array}$ \\
\hline $\mathrm{R}_{3}$ & 0.35 & $\begin{array}{c}\text { Cable resistance between source } \\
\text { and running rail }\end{array}$ \\
\hline $\mathrm{R}_{4}$ & 10.4412 & Resistance of positive feeding line \\
\hline $\mathrm{R}_{5}$ & 4.9728 & Resistance of running rail \\
\hline $\mathrm{R}_{6}$ & 9.7272 & \\
\hline $\mathrm{R}_{7}$ & 9.4717 & \\
\hline $\mathrm{R}_{8}$ & 4.5110 & \\
\hline $\mathrm{R}_{9}$ & 8.8240 & \\
\hline & &
\end{tabular}

Table 2: $\quad$ Rectifier station and trains in the test system.

\begin{tabular}{|c|c|c|c|c|}
\hline $\begin{array}{c}\text { Source/ } \\
\text { Loads }\end{array}$ & $\begin{array}{c}\text { Locatio } \\
\text { ns [m] }\end{array}$ & $\begin{array}{c}\text { Req'd Pwr } \\
{[\mathrm{kw}]}\end{array}$ & $\begin{array}{c}\text { Injection Current [A] } \\
\text { After load flow } \\
\text { analysis }\end{array}$ & Remarks \\
\hline $\begin{array}{c}\text { Rectifier } \\
\text { Station }\end{array}$ & 2670 & 1030.9493 & $\begin{array}{c}\text { Source } \\
\text { Resistance } \\
=0.0225 \Omega\end{array}$ \\
\hline Train_1 & 1427 & 200 & 256.0867 & Regenerating \\
\hline Train_2 & 3262 & -627.2 & -805.4106 & \\
\hline Train_3 & 4420 & 1184.3 & 1580.2787 & \\
\hline
\end{tabular}

locations are shown in Table 1 . In the test system, the rectifier produces $810 \mathrm{~V}$ DC with no load, and three trains are drawing power, as shown in Table 2. The rail potentials of the test system are obtained from the developed load flow software. The results are shown in Fig. 7. The same rail potentials were analyzed with EMTP-RV s/w. Fig. 8 shows the EMTP-RV model of the test system. However, EMTP-RV cannot conduct a DC load flow study, therefore, instead of the power required for the trains, the injection currents from the load flow software are inserted as a DC current source at the train location. This can be validated once the power consumption of each train is identical to its required

\begin{tabular}{|c|c|c|c|c|c|c|}
\hline no, & type & location & volt [u] & src_type & power [kw] & Name \\
\hline 1 & $\mathbf{t}$ & 1427 & -2.471888 & $\bar{c}$ & 200.05 & train_2 \\
\hline 2 & p & 2670 & -4.898177 & $\mathbf{n}$ & 811.18 & 101Station \\
\hline $\mathbf{3}$ & $\mathrm{t}$ & 3262 & -1.404086 & c & -627.20 & train_1 \\
\hline 4 & t & 4420 & 12.537014 & c & 1184.36 & train_o \\
\hline
\end{tabular}

Figure 7: Results from simulation s/w. 


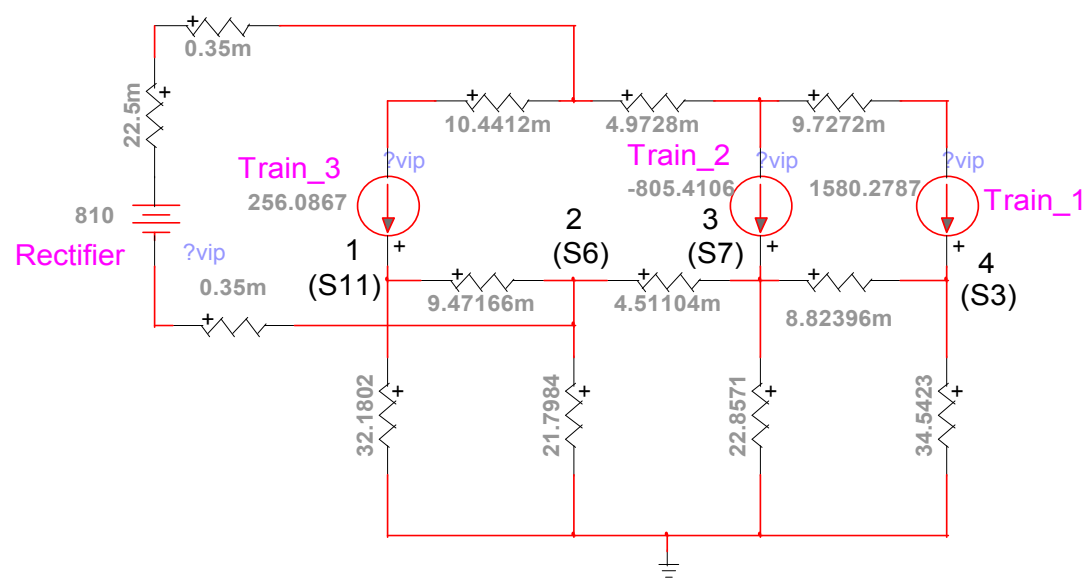

Figure 8: $\quad$ EMTP-RV model of the test system.

power. Fig. 9 shows the resulting rail potentials from the EMTP-RV analysis. The rail potentials from the previous two studies are summarized in Table 3, and the two results are identical. Next, the power that each train consumed according to the EMTP-RV analysis is compared with its required power to validate the

\begin{tabular}{|c|c|c|c|c|c|c|}
\hline & \multicolumn{6}{|c|}{\begin{tabular}{|l|l|} 
Hide & Node Voltages \\
\end{tabular}} \\
\hline & \multicolumn{6}{|c|}{ Hide Node Voltages } \\
\hline & Node & & Real (V) & Imaginary (V) & Module (V) & Phase (degrees) \\
\hline \multirow{4}{*}{ Node_4 } & $s 4$ & 1 & $+0.8047409780 \mathrm{E}+03$ & $+0.0000000000 \mathrm{E}+00$ & $+0.8047409780 \mathrm{E}+03$ & $+0.0000000000 \mathrm{E}+00$ \\
\hline & $s 14$ & 2 & $-0.5259022044 \mathrm{E}+01$ & $+0.0000000000 \mathrm{E}+00$ & $+0.5259022044 \mathrm{E}+01$ & $+0.1800000000 \mathrm{E}+03$ \\
\hline & s3 & 3 & $+0.1253702638 \mathrm{E}+02$ & $+0.0000000000 \mathrm{E}+00$ & $+0.1253702638 \mathrm{E}+02$ & $+0.0000000000 \mathrm{E}+00$ \\
\hline & s17 & 4 & $+0.7619587097 \mathrm{E}+03$ & $+0.0000000000 \mathrm{E}+00$ & $+0.7619587097 E+03$ & $+0.0000000000 \mathrm{E}+00$ \\
\hline \multirow[t]{2}{*}{ Node_3 } & s7 & 5 & $-0.1404087030 \mathrm{E}+01$ & $+0.0000000000 \mathrm{E}+00$ & $+0.1404087030 \mathrm{E}+01$ & $+0.1800000000 \mathrm{E}+03$ \\
\hline & s9 & 6 & $+0.7773303967 \mathrm{E}+03$ & $+0.0000000000 \mathrm{E}+00$ & $+0.7773303967 \mathrm{E}+03$ & $+0.0000000000 \mathrm{E}+00$ \\
\hline \multirow[t]{4}{*}{ Node_1 } & $s 11$ & 7 & $-0.2471894153 \mathrm{E}+01$ & $+0.0000000000 \mathrm{E}+00$ & $+0.2471894153 \mathrm{E}+01$ & $+0.1800000000 \mathrm{E}+03$ \\
\hline & $s 16$ & 8 & $+0.7785098083 \mathrm{E}+03$ & $+0.0000000000 \mathrm{E}+00$ & $+0.7785098083 \mathrm{E}+03$ & $+0.0000000000 \mathrm{E}+00$ \\
\hline & s1 & I9 & $+0.7815444950 \mathrm{E}+03$ & $+0.0000000000 \mathrm{E}+00$ & $+0.7815444950 \mathrm{E}+03$ & $+0.0000000000 \mathrm{E}+00$ \\
\hline & s5 & & $+0.7811836608 \mathrm{E}+03$ & $+0.0000000000 \mathrm{E}+00$ & $+0.7811836608 \mathrm{E}+03$ & $+0.0000000000 \mathrm{E}+00$ \\
\hline & $s 6$ & & $-0.4898187864 E+01$ & $+0.0000000000 \mathrm{E}+00$ & $+0.4898187864 \mathrm{E}+01$ & $+0.1800000000 \mathrm{E}+03$ \\
\hline
\end{tabular}

Figure 9: $\quad$ EMTP-RV analysis results.

Table 3: $\quad$ Rail potential comparison between the results of two studies.

\begin{tabular}{|c|c|c|c|c|}
\hline & \multicolumn{2}{|c|}{ Rail potential [V] } & & Remarks \\
\hline $\begin{array}{c}\text { Node } \\
\text { No }\end{array}$ & $\begin{array}{c}\text { From the } \\
\text { simulation s/w }\end{array}$ & $\begin{array}{c}\text { From EMTP_RV } \\
\text { analysis }\end{array}$ & $\%$ error & \\
\hline 1 & -2.47189 & -2.47189 & 0.00 & Train_3 \\
\hline 2 & -4.89818 & -4.89819 & 0.00 & DC Source \\
\hline 3 & -1.40409 & -1.40409 & 0.00 & Train_2 \\
\hline 4 & 12.53701 & 12.53703 & 0.00 & Train_1 \\
\hline
\end{tabular}


replacement of the required powers in the test system with the DC current sources in the EMTP model. Fig. 10 shows the power consumed by each train and by the rectifier, which are compared to the required powers in Table 4 . The two results are again identical. In Table 4, the output power from the rectifier is $835.09 \mathrm{~kW}$, while Fig. 7 shows a rectifier output power of $811.18 \mathrm{~kW}$, because the rectifier output power in the load flow study includes the $\mathrm{i}^{2} \mathrm{r}$ loss in the $0.225 \Omega$ source resistance. If we add the $\mathrm{i}^{2} \mathrm{r}$ loss to $811.18 \mathrm{~kW}$, we obtain $835.09 \mathrm{~kW}$, which is the rectifier output power before its internal resistance. In Fig. 8, 1-4 are the node numbers of the train and rectifier nodes in the developed load flow software, and S3, S6, S7 and S11 are the node numbers of the train and rectifier nodes in the EMTP-RV model. Fig. 7 and Fig. 8 show the rail potential analysis results from the EMTP-RV analysis and the simulation software developed using the presented algorithm, respectively.

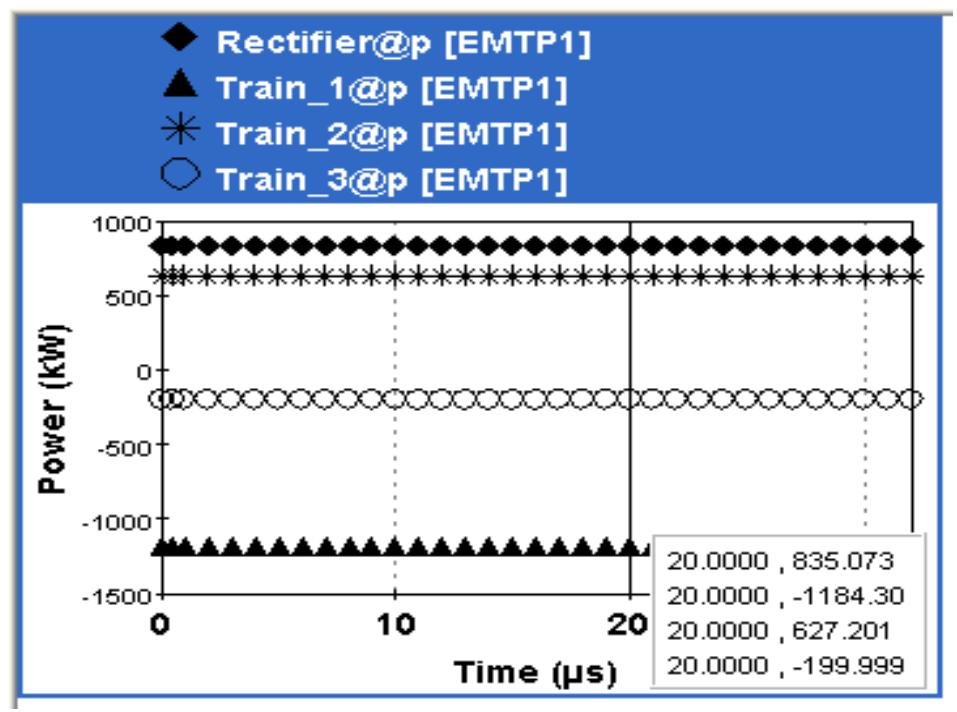

Figure 10: $\quad$ Power generation in the trains \& DC source.

Table 4: Comparison of the power consumption results of the two studies.

\begin{tabular}{|c|c|c|c|}
\hline & \multicolumn{2}{|c|}{ Power Consumption [kW] } & \\
\hline Node & $\begin{array}{c}\text { Require power in the test } \\
\text { system }\end{array}$ & $\begin{array}{c}\text { Results from the } \\
\text { EMTP_RV } \\
\text { analysis }\end{array}$ & \% error \\
\hline Train 3 & 200.0 & 200.0 & 0.00 \\
\hline DC Source & $\begin{array}{c}-835.09 \\
\text { (before internal } \\
\text { resistance of the rectifier) }\end{array}$ & -835.07 & 0.00 \\
\hline Train_2 & -627.2 & -627.2 & 0.00 \\
\hline Train_1 & 1184.3 & 1184.3 & 0.00 \\
\hline
\end{tabular}




\section{Conclusion}

The rail potentials in a DC traction power supply system can be analyzed by applying the node voltage analysis method twice consecutively with the proposed algorithm. This algorithm was validated in section 4 . The advantage of the algorithm is that we can avoid the mesh current method in the rail potential analysis, which is difficult to use because assumed initial mesh currents must be used in the iterative circuit analysis. The mesh current method also requires more than twice the computer memory required for the node analysis method, because the number of meshes is more than twice the number of nodes.

\section{References}

[1] Jian Guo Yu B.Sc.: 'Computer Analysis of touch voltages and stray currents for DC railways', thesis for Ph.D. University of Birmingham, July, 1992.

[2] Pham, K.D., Thomas, R.S. and Stinger, W.E. 'Operational and safety considerations in designing a light rail DC traction electrification system', Proc. 2003 IEEE/ASME Joint, PP.171-189.

[3] IEC62128-1: 'Railway applications - Fixed installations - Part 1: Protective provisions relating to electrical safety and earthing'. 